\title{
FRONTEIRAS NACIONAIS, FRONTEIRAS LITERÁRIAS E AS METAMORFOSES DA DOMINAÇÃO SIMBÓLICA
}

\section{NATIONAL BOUNDARIES, LITERARY BOUNDARIES, AND THE METAMORPHOSIS OF SYMBOLIC DOMINATION}

\author{
Mariana Barreto*
}

0 que o artigo de Pierre Bourdieu Existe uma literatura belga? Limites de um campo e fronteiras políticas teria a nos dizer de modo a justificar sua tradução no Brasil? ${ }^{1}$ De antemão, eu diria que as ideias fortes apresentadas encorajam sua leitura a qualquer tempo, assim como seu problema primordial, isto é, a existência de uma literatura dependente literariamente e autônoma politicamente. Se examinada à luz de uma dependência simbólica que desarruma estratégias de dominação entre centros e periferias, tal problemática deixa ver, segundo o próprio autor, uma "especificidade da dominação literária" (DUBOIS e BOURDIEU, 1999, p.13). Ao discutir a posição complexa e incerta do campo literário belga, Bourdieu não só manifesta um interesse pelas culturas ou literaturas periféricas, como nos oferece pistas para pensarmos as metamorfoses das relações de dominação operadas nas esferas artísticas. As assimetrias entre culturas dominadas, minoritárias, e dominantes são trabalhadas em movimentos que excedem as fronteiras das artes e das nações. 0 leitor brasileiro poderá refletir sobre a coincidência ou não entre suas fronteiras nacionais e as fronteiras dos campos da produção simbólica; poderíamos nos indagar, por exemplo, sobre as relações entre as literaturas brasileira e portuguesa, e de ambas com as angolana, moçambicana ou cabo-verdiana, sobre os papéis da língua

\footnotetext{
* Professora na Universidade Federal do Ceará - UFC - (Fortaleza/CE/BR). Doutora em Sociologia pela Universidade Estadual de Campinas. E-mail: mariana.barreto@pq.cnpq.br

1. Agradeço a Jérôme Bourdieu a autorização para a tradução e publicação deste artigo, assim como o encorajamento de Afrânio Garcia e a leitura final, tanto da Apresentação quanto da tradução, do Prof. Sérgio Miceli.
} 
e das instituições nacionais no estabelecimento dos limites de seus campos ou subcampos literários. Reconheceríamos que, nos processos de construção das diferenciações dos campos nacionais das produções culturais, a existência de instituições nacionais, ainda que produtoras de um efeito interno de campo, e apesar de não excluírem relações costumeiras de tutela e de dominação, têm nas fronteiras linguísticas formas distintas de movimentar tais dependências (JURT, 2009, p. 214-215).

A originalidade para o exame destas questões se coloca quando o autor apresenta a "dependência simbólica" como mecanismo importante que faz funcionar a dominação literária, manifesta nas relações entre centros e periferias. 0 conceito de autonomização é interpelado por situações onde as relações entre autonomia e heteronomia no interior de um campo aparecem regraduadas. Na medida em que a defasagem estrutural entre as hierarquias no campo literário francês e as hierarquias no seio das instituições nacionais belgas, inaugurada pelo estabelecimento das fronteiras políticas (e seu arbitrário jurídico), é ela mesma a própria reprodutora da relação de dependência simbólica entre os dois campos nacionais. Tal diferença tem, por conseguinte, força redobrada: é reprodutora e artífice da dependência simbólica (BOURDIEU, 1985, p. 6). Noutros termos, as relações entre autonomia e heteronomia se complexificam porque vinculam-se também às mediações operadas pelas posições ocupadas nas classificações específicas de cada campo. Portanto, a independência não vem exclusivamente do dinheiro, por exemplo, os dominados em um campo, por mais propício que estes sejam à heteronomia, nem sempre se curvam às demandas da igreja, do partido ou do Estado; assim como os consagrados, os mais livres em seus campos podem ser tão submissos quanto os dominados (DUBOIS e BOURDIEU, 1999, p.17).

As relações de dominação simbólica colocadas nestes termos descentram a afirmação da autonomia sobre às demandas ideológicas e econômicas, reforçando a importância do interesse dos pesquisadores pelas análises dos princípios de oposição estrutural que regem a atividade e a competição específica entre os estabelecidos e os grupos que ocupam posições dominadas dentro de um campo ${ }^{1,}$ numa perspectiva relacional capaz de identificar as injunções que transformam os "dominados em grandes, dentre os pequenos”, que leva os povos estigmatizados a "fazer da necessidade uma virtude", destacando-se naquilo que é abandonado a eles porque desprezado pelos dominantes. (Id. Ibidem). É nesse movimento que as dependências se complexificam, isto é, valões e flamengos ainda que duplamente dominados: fora e no interior do espaço literário

1. Gisèle Sapiro (2019) procura desfazer as confusões em torno dos múltiplos significados acumulados pelo conceito de autonomia nas ciências humanas. Ela irá revisar as três tradições que fizeram uso sistemático do conceito, cujas camadas de sentido, sedimentadas ao longo dos anos de 1950-1960, ajudam a alimentar a habitual confusão que aí se encontra. No artigo, a autora acredita que as camadas sobrepostas de sentido, operadas por uma sociologia das profissões, pela teoria do reflexo marxista e pela teoria dos campos, se bem diferenciadas e sintetizadas de modo razoável, podem funcionar bem para a análise da produção e circulação dos bens simbólicos. 
francófono belga têm suas posições hierárquicas alteradas se observarmos como o reconhecimento e a consagração se distribuem do ponto de vista da identificação e da alteridade dentro do espaço nacional. Os escritores que representam a literatura nacional, os mais reconhecidos como belgas, são os flamengos, minoritários se comparados aos valões, dominantes entre os escritores nacionais, porque reconhecidos no campo literário francês. Aí reside uma das excepcionalidades da reflexão de Bourdieu, as posições ocupadas pelos agentes, pelas práticas e instituições no interior de um campo perdem em valor heurístico se apreendidas como regidas por regularidades (leis) mecânicas, e não tendenciais.

0 pequeno artigo publicado na Suiça reforça que a virtude explicativa do conceito de campo não reside tanto em sua definição espacial, quanto na historicidade e temporalidade própria que ele assume (SAPIR0, 2013, p. 85). Concebe as formas de territorialidade cultural como menos unívocas, dá a ver como a mecânica polarização centros culturais e periferias encobre as dinâmicas criadoras de novas legitimidades culturais capazes de descentrar as rígidas identificações entre metrópoles e províncias, dentro e fora de seus limites nacionais. Não sem desconsiderar a força das hierarquias que aí se estabelecem, mas remirando igualmente as produções locais, ou seja, aquelas essencialmente vinculadas às metrópoles, mas capazes de fazer do local fonte essencial para sua influência nacional e internacional (WILFERT-PORTAL, 2010, p. 179). As formas como os povos reagem à dominação criam os "exotismos e os temperamentos literários”, os "mitos do terroir", as "almas nacionais", representações que justamente, por produzirem e reforçarem a dependência simbólica, incrementam as relações entre autonomia e heteronomia dentro e fora dos campos nacionais.

Bourdieu (1985, p. 4) é enfático ao afırmar que esta dependência está "nas estruturas e nas mentes" ensejando e dissuadindo as práticas dos agentes, instituições, e ativando os efeitos do campo. Contudo, as instâncias heterônomas aí forjadas enfrentam a ambivalência que caracteriza, no caso belga, a lógica própria do campo literário dominante (parisiense) e a lógica política local (relativa, por exemplo, à organização de uma literatura nacional pelo Estado). A hipótese que se confirma é a de que a vida literária belga é um subcampo do campo literário francês, separado por uma fronteira política. Em tempos de discussões sobre a existência dos campos transnacionais, podemos ler o esforço reflexivo de Bourdieu a partir de uma perspectiva mais linear, tal como a colocada por Aron (2011), centrada sobre a eficácia da precisão de uma definição daquilo que seria um subcampo. Em suas palavras,

Toda a questão é, com efeito, saber o que a noção de subcampo é capaz de descrever. Se se trata, antes de tudo, de dar conta da posição de um conjunto literário periférico no seio do campo literário francês, a análise terá por efeito principal caracterizá-lo por sua posição relativamente dominada pelo centro parisiense; então, colocar-se-á em evidência o reduzido grau de autonomia do subcampo belga, sua menor capacidade para produzir capital simbólico e, consequentemente, sua diminuta capacidade para produzir valores literários negociáveis junto ao centro parisiense; ou ainda, insistir-se-á sobre a propensão deste subcampo para reproduzir em sua escala e para seu próprio uso os modos de estruturação e de hierarquização em vigor nas zonas mais legitimas do campo. Di- 
to de outro modo, a descrição frequentemente se assemelhará a uma constatação das lacunas e, portanto, a uma descrição negativa do conjunto literário assim estudado. Mas ela pode também conduzir a insistir sobre a estruturação específica dos jogos e desafios literários em um país onde a história e as tradições não revelam as lógicas da República vizinha (p.16-17).

Assim como podemos lê-lo sob o prisma do reflexo multiangular das relações de dependência entre campos centrais e campos periféricos, a ponto de explicar como suas topografias hierárquicas são alteradas, quando autonomizamos metodologicamente o conceito de campo, quando deslocamos suas fronteiras para além dos perímetros dos Estados-nação. (SAPIRO, 2013). Fenômenos de circulação, trocas e transferências entre campos e subcampos da produção cultural desarranjam os esquemas que rechaçam (ou rechaçaram um dia) as especificidades das relações de heteronomia no interior dos campos ou dos subcampos. Por fim, hoje, o que cintila no artigo de Bourdieu, e assevera sua tradução no Brasil, reside, talvez, sobretudo, nas pistas que oferece para refletirmos sobre a força simbólica que sempre possuíram as culturas minoritárias. As diaspóricas constituem um exemplo fecundo, na medida em que, ontem sob a insígnia constitutiva das identidades nacionais e hoje como evidência de certo cosmopolitismo, funcionaram e funcionam como substrato estruturante para uma história transnacional das produções culturais mundo afora.

\section{Referências}

ARON, P. Introduction. Cahiers de l'Association Internationale des Études Françaises, n. 63, p. 1125, 2011.

BOURDIEU, P. Existe-t-il une littérature belge? Limites d'un champ et frontières politiques. Études de Lettres, n. 4, p. 3-6, 1985.

DUBOIS, J.; BOURDIEU, P. Champ littéraire et rapports de domination. Un entretien de Jacques Dubois avec Pierre Bourdieu. Textyles - Revue des Lettres Belges de Langue Française, n. 15, p. 1216, 1999.

JURT, J. Le champ littéraire entre le national et le transnational. In: SAPIRO, G. (Org.). L'espace intellectuel en Europe - De la formation des Étatsnations à la mondialisation XIXe - XXIe siècle. Paris: la Découverte, 2009, p. $201-232$.

SAPIR0, G.; LEPERLIER, T. E BRAHIMI, M.A. Qu'est-ce qu'un champ intellectuel transnational? Actes de la Recherche en Sciences Sociales, Champs Intellectuels Transnationaux, n. 224, p. 4-12, 2018.

SAPIRO, G. Repenser le concept d'autonomie pour la sociologie des biens symboliques. Biens Symboliques, n. 4, p. 2-50, 2019.

Le champ est-il national ? La théorie de la différenciation social au prisme de l'histoire globale. Actes de la Recherche en Sciences Sociales, Théorie du Champ, n. 200, p. 71-85, 2013.

VIALA, A. Effets de champ et effets de prisme. Littérature, n. 70, p. 64-71, 1988.

WILFERT-PORTAL, B. L'internationalité d'un nationaliste de Paris: Paul Bourget entre Paris, Londres et Rome. In: BOSCHETTI, A. (Dir.). 2010. L'Espace Culturel Transnational. Paris: Nouveau Monde, 2010, p. 165-194.

Recebido em: 24/01/2020

Aprovado em: 05/03/2020 